\title{
LOS GENOVESES Y EL NEGOCIO DE LA SEDA EN VALENCIA (1457-1512)
}

\author{
GERMÁN NAVARRo EsPinach \\ Universidad de Valencia
}

\begin{abstract}
SUMARIO
I. Introducción. - II. Del salvoconducto de los Gavoto en 1457 al mercado textil de 1512. - III. Promoción técnica y triunfo comercial del terciopelo negro.- IV. Tipos de perfiles sociales entre los emigrantes.- V. Conclusiones.
\end{abstract}

\section{INTRODUCCIÓN}

Durante los días 16-18 de junio de 1995 se ha celebrado en Pisa un seminario internacional titulado Commercio a lunga distanza e sviluppo delle economie regionali nel Mediterraneo medievale. El comité organizador formado por Marco Tangheroni, Giuseppe Petralia y Laura Galoppini propuso discutir cuáles fueron los efectos del comercio a larga distancia en el desarrollo o reorientación de las economías regionales de los siglos XI$\mathrm{XVI}^{1}$. Sin duda alguna, el debate ha servido de estimulo para el estudio de la presencia genovesa en la Valencia tardomedieval. En realidad, según los propios coordinadores esta reunión marcaba continuidad respecto a un primer seminario celebrado en la misma Valencia en abril de 1994 sobre $E l$

\footnotetext{
'Este seminario de excelentes resultados contó con la participación de especialistas como D. Abulafia, M. Aymard, M. Del Treppo, S. R. Epstein, P. Iradiel, D. Jacoby, G. Rossetti o I. Wallerstein, siendo clausurado de manera brillante por las reflexiones conclusivas de $A$. Grohmann.
}

"Anuario de Estudios Modievalos", 24 (1994) 
Mediterraneo y la idea de Europa en el tránsito de la Edad Media a la Moderna: espacios, culturas, intercambios, élites, dirigido por Paulino Iradiel $^{2}$, coincidiendo además con la apertura del primer curso académico de la Escuela de Especialización Superior en Historia del Mediterráneo de la Comunidad de Universidades Mediterráneas (CUM) con sede en Valencia, versado asímismo sobre El Mediterráneo en época de los Descubrimientos. El impacto económico.

Hablar de comercio y navegación en el Mediterráneo medieval significa, por tanto, estar de actualidad en términos de perfiles investigadores y de debate entre medievalistas e historiadores de la economía. En ese sentido y por lo que afecta a la integración de los genoveses en muchas ciudades de Europa, reivindicaba Gabriella Airaldi firmemente y con gran acierto que "e d'obbligo fare a meno di tornare sempre sui luoghi comuni d'una storia mediterranea fine a se stessa: nella quale, invece, tanto il mare quanto le vicende della diaspora genovese devono essere intesi, come in realtà furono, nodi di comunicazione di sapere e di moduli di vita in bilico tra un vecchio e un nuovo mondo e tra mondi diversi" ${ }^{3}$. De un lugar para otro a través del Mediterraneo se han movido las ideas con las personas y los objetos de múltiples maneras, tanto en la forma de experiencias de visualización directa como por trasmisión oral y aprendizaje, constituyendo así un aspecto básico para toda cultura medieval que aspire a ser correctamente definida. Ambito éste sobre el cual ahora parece necesario conducir una indagación más cuidada que restituya y reintegre de una vez por todas la evolución ideológica del saber técnico y de la moda en el universo económico-político de la producción para el mercado, y lo haga por ejemplo a partir del análisis de procesos de gran riqueza fenomenológica como fueron entre otros la circulación de élites mercantiles, de maestranza técnica y de mano de obra asalariada de ciudad en ciudad a lo largo de la que también se ha venido en llamar la vieja Europa del mar.

Desde esos presupuestos de reflexión asumidos de pleno, la diáspora genovesa en el Mediterráneo de los siglos medievales ya no se explicará

\footnotetext{
${ }^{2}$ Las actas de esta reunión van a ser publicadas en el número 6 de la "Revista d'Història Medieval" de Valencia. Para una aproximación historiográfica previa sobre la construcción del sistema europeo de relaciones pueden verse las actas del congreso organizado por el Istituto Storico Italo-Germanico di Trento en 1990 con especial atención al trabajo de G. RoSSETn, Idea d'Europa nel Medioevo o realid europea del Medioevo?, "Der Europa Gedanke", Tubbingen, 1992, pp. 58-68.

${ }^{3}$ G. AIRAIDI, Genova e la Liguria nel Medioevo, Torino, 1986, p. 9.
} 
aquí simplemente como marítima y mercantil bajo la presión ejercitada en forma única por intereses de grupos empresariales o de hombres de negocios. Ya no puede entenderse sólo así para quienes la descubren en la Valencia de la segunda mitad del siglo XV o de los primeros años del XVI. Una ciudad mediterránea de la Corona de Aragón, donde no es exagerado afirmar que en efecto c'era un'altra Genova: la Génova de los numerosos mercaderes y artesanos de la seda que promocionaron sus famosos velluti. Todo un mundo que revoluciona y supera cualquier explicación económica del tema, trasladando al historiador al terreno de la sociología y de la antropología para el estudio de esas relaciones comerciales, de esa difusión de saber técnico y de esa historia de la moda textil, en manos de ricos intercambios de experiencias que homogeneizaron más y más el incipiente sistema europeo ${ }^{4}$.

Contextualizados en la historia de la seda en Valencia durante la baja Edad Media ${ }^{5}$, se intentará dar respuesta al menos a tres cuestiones que emergen inicialmente cuando se pretende explicar el proceso de llegada e integración masiva de estos emigrantes en el "negocio de la seda" de la ciudad de Valencia. Sobre todo, tras contrastar los resultados de investigación en los archivos genoveses con la cuantiosa documentación valenciana, en colaboración con el Istituto di Storia del Medioevo e dell'Espansione

\footnotetext{
${ }^{4}$ Considero como punto de partida fundamental las ideas sobre la alta movilidad social de la baja Edad Media expuestas por R. COMBA, Emigrare nel Medioevo. Aspelti economicosociali della mobilità geografica nei secoli XI-XVI, "Strutture familiari, epidemie, migrazioni nell'Italia medievale, Nápoles, 1984, pp. 45-74; G. PINTO, Forestieri e stranieri nell'ltalia comunale: considerazioni sulle fonti documnentarie, "Foresticri e stranieri nelle città bassomedievale", Florencia, 1988, pp. 19-27; ID., Gli stranieri nelle realıà locali dell'ltalia bassomedievale: alcuni percorsi tematici, "Dentro la città. Stranieri e realtà urbane nell'Europa dei secoli XII-XVI", Nápoles, 1989, pp. 23-32; y A. GrOHMANN, Élites intemacionali e sistemi di aziendi nell'Europa dei secoli XIII-XVI: Tipologia delle ricerche possibili, "Bolletino GISEM", 3 (1992-1994), pp. 50-69.

${ }^{3} \mathrm{Cfr}$. G. NAVARRO ESPINACH, El despegue de la industria sedera en la Valencia del siglo XV, Valencia, 1992; ID., L'artisanat de la soie d Valence d la fin du Moyen Age, "Razo. Cahiers du Centre d'Études Médiévales de Nice", 14 (1993), pp. 163-175; ID., Velluteros ligures en Valencia (1457-1524): la promoción de un saber técnico, "Le vie del Mediterraneo: idee, uomini, oggetti (secoli XI-XVI)", Génova, en prensa; y P. IRADIEL MURUGARREN y G. NAVARRO ESPINACH, La seda en Valencia en la Edad Media, "España y Portugal en las Rutas de la Seda", Valencia, en prensa. La revisión y culminación de todos esos estudios se encuentra en G. NAVARRO ESPINACH, Industria y artesanado en Valencia, 1450-1525. Las manufacturas de seda, lino, cánaino y algodón, tesis doctoral (título de Doctorado Europeo), dirigida por el profesor Paulino Iradiel, en microficha, 4 vols., Universitat de València, 1995.
} 
Europea de Génova ${ }^{6}$. ¿Cuándo comienza la emigración y por qué Valencia se convierte en el destino preferente?, ¿Qué efectos en ámbito productivocomercial y qué novedades culturales se gestaron con los genoveses en la sedería valenciana?, y ¿Cuáles fueron sus biografías-tipo o perfiles sociales más comunes?. Las tres reflexiones querrán recuperar a estos emigrantes del pasado para hacerlos partícipes activos de le vicende della diaspora -de la historia "externa" de la dominación de Génova- pero también contribuir a la historia "interna" que reclamaba Giovanna Petti Balbi al mencionar la necesidad de "cogliere taluni componenti, taluni aspetti della dinamica cittadina e dell'integrazione tra Genova e il Mediterraneo, per sottolineare il rapporto tra la citta e il mare, un rapporto di cui affiora la consapevolezza negli uomini e nelle cose per radicarsi poi nel bagaglio culturale e nella memoria collettiva"?.

\section{Del salvoconducto de los Gavoto en 1457}

\section{AL MERCADO TEXTIL DE 1512}

La creación del Arte della Seta en Génova en 1432 no sólo fue eco de la expansión y del prestigio de la potente industria local, sino también marcó efectos culturales de largo alcance al otro lado del Mediterráneo. Entre estos efectos se descubrió al principio cierta trasferencia tecnológica hacia Cataluña según mostraban algunas noticias del Archivo Municipal de

\footnotetext{
'Dentro del Plan de la Generalitat Valenciana para la Formación y Perfeccionamiento de Profesores e Investigadores Universitarios en el Extranjero, durante el curso 1993-1994 se realizó el proyecto titulado La emigración de sederos genoveses a Valencia (siglos XV-XVI): causas de movilidad y trayectorias familiares de clase en el Istituto di Medievistica de la Universidad de Génova, a cuya directora la profesora Gabriella Airaldi quiero manifestar mi agradecimiento. Este proyecto implicó el manejo de documentación conservada en fondos del Archivio di Stato (secciones de Antico Comune, Archivio Segreto, Notai Antichi, Officium Monetae, Uffizi delle Arte) y del Archivio Storico del Comune (secciones de Padri del Comune, y fondos Giulio Pallavicino y Giovanni Brignole) así como la consulta fundamental de la base de datos informática ARTIGEN, gracias a la gentileza de los profesores Carola Ghiara y Giacomo Casarino del Centro di Studi per la Storia della Tecnica in Italia. Quiero agradecer asímismo la ayuda prestada por la profesora Paola Massa del Istituto di Storia Economica, y por la Dra. Sagginati del Archivio Storico del Comune. Los resultados se han completado recientemente dentro del mismo plan para el curso 1994-1995 con el proyecto titulado Industrias textiles del Mediterráneo occidental. Valencia y las ciudades italianas en los siglos XV. XVI, adscrito al Istituto di Storia Economica de la Universidad de Bari en colaboración con su director el profesor Antonio di Vittorio a quien expreso igualmente mi agradecimiento.
}

'G. PETT BALBI, Una ciltd e il suo mare. Genova nel Medioevo, Bolonia, 1991, p. 11. 
Barcelona, publicadas hace ahora casi cincuenta años por Durán Sempere ${ }^{8}$. Era la identificación de los maestros de brocados Urbano Trincherio, Baldassarre Migliolino y Domenico di Lucca, presentes en Barcelona hacia 1451. Las autoridades municipales discutieron la conveniencia de proteger a estos extranjeros que habían venido con ánimo de establecer allr una nueva industria para la ciudad: la fabricación de tejidos de oro y seda. Ciertamente, Trincherio, Migliolino y Lucca viajaron desde Génova a Barcelona para solicitar que se les subvencionase por parte de la ciudad con 10.000 florines, y se les concediera el derecho de ciudadanía, así como el monopolio exclusivo para producir brocados puesto que en la ciudad de Barcelona no existía tal producción.

Tiempo después, Jacques Heers se percató del asunto desde la serie de decretos de gobierno del Archivio di Stato al encontrar una referencia sobre el mencionado Urbano Trincherio cuando fue repatriado y condenado por el doge Pietro di Campofregoso a solicitud del Arte en 1452, tras haber emigrado ad partes Catalonie exportando instrumenta et artificia ${ }^{9}$. Detrás de este ejemplo se insinuaba una cuestión de mayores dimensiones que recogería Paola Massa en su libro sobre la industria sedera genovesa: "Sono numerosi i documenti in cui si fa menzione di città o paesi in cui gli artigiani genovesi della seta si trasferirono, con maggiore o minore fortuna: l'isola de Chio, la Catalogna, le città di Trento, Mantova, Vincenza e Ferrara. Si trata, specialmente nei primi due casi, di luoghi in cui era presente in abondanza la materia prima, sia perche prodotta sul posto, sia in quanto oggeto di un notevole commercio"10.

Sin embargo, en el trasfondo de la expresión ad partes Catalonie acabó siendo Valencia y no Barcelona la receptora de una masiva inmigración de sederos genoveses. La repatriación de Trincherio a Génova manifestaba ya cierto fracaso en la promoción del arte de los brocados en Barce-

${ }^{8} \mathrm{~A}$. DURÁN SEMPERE, Brocados y maestros brocateros en el siglo XV, "Barcelona. Divulgación histórica", 5 (1948), pp. $83-87$ (artículo redactado el 1 de abril de 1945).

'J. HEERS, Gênes au XVe siècle. Activité économique et problèmes sociaux, Paris, 1961, p. 236. El decreto de condena de Trincherio se puede encontrar en el Archivio di Stato di Genova, Archivio Segreto, Diversorum Communis lanue, 1452-1453, no 3.040, filza 253 (1452-IV-13). Este documento está localizado a su vez por Paola Massa como el decreto Nemo portet artein extra porque se reseñó paralelamente en el Liber secundus decretorum et seu capituloruin artis seaterioruin, ab anno 1432 usque ad 1562 (c. 29v) de la Biblioteca Universitaria di Genova; véase P. MASSA, L'arte genovese della seta nella norınativa del XV e del XVI secolo, Génova, 1970, p. 195, nota 35 especialınente.

${ }^{10}$ Bidein, p. 192. 
lona. Esta idea está confirmada por Durán en su artículo antes citado mediante otro documento donde aparece un maestro hilador de oro, natural de Valencia, que intentaba instalarse en Barcelona en 1458 con su familia y otros cuatro matrimonios artesanos del oficio. Será entonces cuando el municipio barcelonés todavía argumente que la introducción del arte de los brocados en la ciudad era verdadera novedad pues allí no se producía como sucedía ya en otros lugares"

En consecuencia, mientras el colectivo de sederos judeoconversos debio absorber pues la mayor iniciativa en la producción barcelonesa, por esas mismas fechas en Valencia ya trabajaban algunas empresas ligures en la sedería además del artesanado judeoconverso local. El 16 de noviembre de 1457, Alfonso V había concedido un salvoconducto a Gaspare Gavoto, Bernardo Gavoto y Luca di Prè, mercaderes de Savona, para instalar en Valencia su "industria in texendis pannis siricis, papiri conficienda, et aliis multis... ad exercenda officia atque magisteria prelibata cum vestris famulis, ministris, bonis, et rebus omnibusque apparatibus neccessariis" ${ }^{12}$. Y será incluso en correspondencia fechada en 1457 y conservada en el Archivo Municipal de Barcelona donde aparezcan informaciones sobre un poderoso mercader Ilamado Gaspare Gavoto, procedente de Savona, establecido hacía más de 12 años en Valencia, es decir, al menos desde 1445. Gavoto era un empresario de brocados de seda que a través de una misiva de las autoridades municipales de Valencia a las de Barcelona reclamaba que fueran liberados dos maestros savoneses, asalariados suyos que habran sido apresados durante su viaje por mar hacia Valencia, y hechos cautivos en las cárceles de Barcelona por no llevar salvoconducto ${ }^{13}$.

\footnotetext{
"Esta hipótesis está confinnada primero por Claude Carrère cuando ofrece el listado de menestrales italianos en la sedería bareclonesa durante 1455-1460, algunos de los cuales aparecen en nuestro estudio prosopográfico del Manifest de les Sedes del Tall del Drap del General de Valencia (año 1475). Crr. C. CARRt:RE, Barcelona, 1380-1462. Un centre econdmic en época de crisi, 2 vols., Barcelona, 1977, tomo II, pp. 418-419; y G. NAVARRO ESPINACH, Industira y artesanado en Valencia, cit., tomo IV, pp. 1246-1257. En esa misma línea se expresa también M. SÁNCHIZZ MARTINIZZ, La seda a la Catalunya medieval, "El món de la seda i Catalunya", Barcelona, 1991, pp. 169-188.

${ }^{12}$ Archivo del Reino de Valencia (=ARV), Real Cancilleria, 259, f. 110. Citado por M. Gual Camarina, Para un muapa de la industria textil hispana en la Edad Media, "Anuario de Estudios Medievales", 4 (1967), p. 156.

${ }^{13} \mathrm{~L}$. Camós Y CABRuJa, Dos genoveses, inaestros de broćados, cautivos en Barcelona, "Barcclona. Divulgación Histórica", 5 (1948), pp. 89-91.
} 
El monopolio de los Gavoto en Valencia no fue un hecho excepcional en la Península Ibérica. Por ejemplo, en 1493 los Reyes Católicos concedían otro privilegfo similar a favor de Agostino Italiano y Martino Centurione para "haser'? labrạr pannos e sedas e lanas e açucares, asy en la cibdad de Málaga como en las çibdades de Granada e Almunnecar"14. En el caso valenciano, èsa iniciativa de los Gavoto marcará la cronología de salida para la intervención genovesa y el despegue de los negocios sederos en la ciudad. La fecha del salvoconducto en 1457 coincide con las declaraciones de los mismos artesanos protagonistas del proceso a través de los testimonios requeridos en un pleito del oficio de velluters contra el de tintoreros de seda hacia principios del siglo XVI. El 9 de abril de 1507, recordaba de su propia memoria el anciano Pere Falco, antiguo clavario del oficio de tejedores de velos, que habla conocido de tiempo de sesenta o setenta años atrás, en torno a 1440 quizás: "que en la dita ciutat de Valencia no y havia velluters, e los dits tintorers de seda ja tenyien les sedes... que alguns velluters los quals eren venguts de Genova a la present ciutat de Valencia, e de altres parts del Llevant, ha vist ell dit testimoni que.s posaven a tenyir sedes no éssent lo dit offici de tintorers offici format"15.

El primer reflejo de la presencia de sederos ligures en la documentación notarial de Valencia confirma también esa cronolog ́a aducida. El 18 de agosto de 1457, Lupecino di Borlasca, mercator januensis et magister faciendi sericem sive sedam, contrató para 5 años al aprendiz lombardo Giacomo Ferrando de 15 años de edad, siendo testimonio del acto ante el notario Joan Montfort precisamente el empresario Luca di Pre de Savona, que aquf aparecerá bajo la denominación de mercator januensis commorans Valencie $^{16}$. También entre la clientela del mismo notario Joan Montfort en 1468 estarán otros destacados artesanos ligures contratando aprendices,

${ }^{14}$ Cfr. J. E. LOPEZ DE COCA CASTAÑER, Los genoveses en Málaga durante el reinado de los Reyes Católicos, "Anuario de Estudios Medievales", 10 (1980), pp. 619-650; J. E. LOPEZ DE COCA CASTAÑER y M. T. LÓPEZ BELTRAN, Mercaderes genoveses en Málaga (1487. 1516). Los hermanos Centurión e Ytalian, "Historia. Instituciones. Documentos", 7 (1980), pp. 95-123. Véanse asímismo las nuevas aportaciones documentales de G. NAVARRO ESPINACH, La seda entre Génova, Valencia y Granada en época de los Reyes Católicos, "La frontera oriental nazari como sujeto histórico", Lorca-Vera, en prensa.

is Archivo del Colegio del Arte Mayor de la Seda de Valencia (=ACAMSV), Lg. 3.3.1., Procesos, $n^{\circ} 4$, f. $212 \mathrm{v}$.

${ }^{16}$ Archivo de Protocolos del Patriarca de Valencia (=APPV), notario Joan Montfort, signature 24.046 . 
formando compañfas o recibiendo actos de dote: Pietro di Barbagelata, Battista di Lacomarcino, Benedetto di Matro, Giovanni di Rapallo, Giovanni Battista di Rapallo, Raffaele di Rapallo y Nicola di Ugo. Se les suele calificar como textores pannorum sericis januenses commorantes Valencie, la típica denominación profesional que asumín mayoritariamente los tejedores de seda en la ciudad de Génova como recoge Lucciana Gatti ${ }^{17}$. Paralelamente, entre los protocolos del notario Jaume Albert durante 1469-1471 se puede seguir la pista a otros sederos ligures como Cristoforo Machalufo, Gerolamo di Roncho o Adamo Rosso, sederii januenses pro nunch commorantes Valencie, relacionados en diversos negocios con los mercaderes Gavoto de Savona ${ }^{18}$. El caso de Cristoforo Machalufo -más tarde identificado como velluter genovés- encajará incluso en la referida cronología con sus propias declaraciones personales cuando intervenga en el pleito antes citado de 1507 para explicar que hacía unos 35 años que habŕa llegado a Valencia, es decir, a principios de los años setenta tal y como refleja su primera presencia conocida en el notario Albert.

Desde 1457, el motor de la circulación de élites mercantiles genovesas estaba a pleno rendimiento, manifestándose con claridad en la documentación local y con una tendencia progresiva al alza a partir de 1475. Este fenómeno "sectorial" de la seda coincide sin embargo con un desplazamiento general hacia Valencia en detrimento de Barcelona, de las iniciativas comerciales, bancarias, técnico-mercantiles y productivas de las compañfas genovesas, según han demostrado las investigaciones de Paulino Iradiel y David Igual ${ }^{19}$. Por tanto, una de las explicaciones sobre esta iniciativa de las élites mercantiles genovesas radica en la nueva centralidad de Valencia en el Mediterráneo genovés, tras aquel primer intento de instalación en Barcelona que no encontró la adecuada coyuntura.

\footnotetext{
${ }^{17}$ APPV, notario Joan Montfor, signalura 24.058 (1468-11-7, -12, -20, -111-21, -22, -27, V4 y XII-2). L. GATTI, Un catalogo di mestien, "Macstri c garıoni nclla socictà genovesc fra XV e XVI sccolo (II)" Génova, 1980, pp. 140-142.

${ }^{18}$ APPV, notario Jaume Alber, signaturas 10.205 (1469-V-15) y 11.241 (1471-III-8 y $1471-X-15)$.

${ }^{19} \mathrm{Cfr}$. P. Iradiel Murugarkin, Valencia y la expansión mediterránea de la Corona de Aragón, "La Corona d'Aragó. El Regne de València en l'Expansió Mediterrània (1238-1492)", Valencia, 1991, pp. 81-88; D. IGUAL LUIS, Valencia y Sevilla en el sistema econónico genovés de finales del siglo XV, "Revista d'Història Medieval", 3 (1992), pp. 79-116. Para un conocimiento previo del papel de Valencia medieval como centro de actividad para los italianos véase también D. I(iUAl. LUIS y G. NAVARRO ESPINACH, Le relazioni economiche tra Valenza ed licalia nel XIV secolo, "Mediocvo. Saggi c Rasscgne", 20, en prensa.
} 
Pero la presencia genovesa es muy cuantiosa y no se reduce a una élite protagonista. El estudio prosopográfico sobre múltiples fuentes normativas, fiscales, corporativas y privado-notariales de nuestra tesis doctoral ha desvelado que el $41 \%$ de las 2.652 reseñas biográficas compiladas para el período 1450-1525 son mercaderes y artesanos extranjeros en Valencia. Sólo los emigrantes italianos en el negocio de la seda forman un colectivo de 562 personas, de las cuales 190 declaran venir de la ciudad de Génova aparte de otras trescientas personas de origen homologable en función del análisis antroponimico o de sus propias relaciones familiares ${ }^{20}$.

El estudio comparativo de los Manifests de les Sedes de 1475 y 1512 -conservados con toda riqueza de detalles en el Archivo del Reino de Valencia, junto a su inmediata proyección fiscal dentro del impuesto de la seda aplicado por la Corona a través de la Taula del General del Tall del Drap- demuestra no sólo el "peso del número" sino también el de la acción empresarial de los genoveses en el sector de la seda. Los balances globales de estos gravámenes sobre la producción y comercialización de tejidos comienzan por reflejar un fuerte crecimiento de los intercambios y del número de declarantes y agentes comerciales implicados: de los 137 declarantes de tejidos de 1475 se pasa a los 197 de 1512; de las 204 personas prosopografiadas entre intermediarios y otros para 1475 se pasa a las 495 de 1512 . Igualmente, frente a las 5.443 varas, 1 cuarto y 1 palmo $(=5.443 / 1 / 1$ varas $)$ cortadas de telar y las $11.971 / 0 / 2$ varas, 108 palmos genoveses y 1.034 piezas en almacen que registran los declarantes de 1475 , el montante total de varas compradas para 1512 es de 42.292/0/3 más 36 piezas. Pero, a pesar de ello, la expansión del negocio sedero según las fuentes fiscales con un protagonismo cada vez mayor de mercaderes toledanos que envian partidas de tejidos hacia Castilla, implicó a la inversa el abandono paulatino del mercado por parte de los antiguos promotores genoveses $^{21}$.

En el Manifest de les Sedes de 1475, los genoveses declaraban las partidas más grandes de tejidos cortados en telares de su propiedad o me-

\footnotetext{
${ }^{20} \mathrm{G}$. NAVARRO ESPINACH, Industria y artesanado en Valencia, cit., tomo II, figura 66, pp. 410-427. La figura en cuestión es una tabla sintética de todos los emigrantes italianos en la industria sedera de Valencia (1450-1525), con apellido y nombre, cronología de la presencia, origen geográfico y denominación profesional.

${ }^{21}$ Ibidern, tomo II, figuras 71-72, pp. 539-548. Son los dos balances globales de los declarantes de 1475 y 1512 que tienen como base informativa el tomo IV de la misma tesis.
} 
diante el encargo de trabajo a domicilio (sistema de comandas), en calidad de mercaderes-empresarios: Matteo Grasso (434/0/2 varas), Battista di Lacomarcino (544/3), Cristoforo Machalufo (275/3), Lazzaro Negro (244/012), Francesco Palmaro (350), Gerolamo di Roncho (254/3/2), y Luigi di Sanguineto (261/3). Es decir, sumaban juntos más del $40 \%$ de los tejidos cortados de telar por todos los declarantes de ese año. Mientras tanto, las partidas en almacén eran lideradas por personas como el veneciano Piero Mai (2.604/2/2 varas) o el florentino Giovanni del Vigno (1.931/2 varas). Coyuntura de verdadero monopolio del negocio sedero valenciano que en el mercado textil de 1512 desaparecerá en manos de toledanos, castellanos y aragoneses con miles de varas cada uno, caso de los Aguilar, A!beitar, Latorre, López, Parreño, Pérez Celada, Ramírez, Ribes o. Sánchez Usillo entre otros más. Por contra, de aquella presencia genovesa que fue la verdadera promotora del sector en Valencia quedarán sólo los registros de Lorenzo Gavoto (416/3 varas) o Barnaba di Grimaldo (570/2) como más representativos. En definitiva, la intervención del capital comercial genovés en la esfera de la producción local fue a todas luces el detonante principal del despegue sedero de Valencia. De los 172 telares de terciopelos, satenes y damascos del año 1479 según recuento realizado por los maestros velluters en la documentación gremial, las actas municipales hablarán de hasta 1.200 telares de velluts, cetins, domassos, taffats e sayes de seda en época de las Germanías, que derivarán en 400 hacia 1532 por causa del declive de la industria urbana ${ }^{22}$. Ciertamente, la misma versatilidad típica para los negocios en tiempos del feudalismo tardío había propiciado el final de la inyección genovesa en los primeros años del siglo XVI y su relanzamiento a otros centros o sectores económicos.

\section{PROMOCIÓN TÉCNICA Y TRIUNFO COMERCIAL DEL TERCIOPELO NEGRO}

El estimulo productivo y la expansión de los intercambios en el negocio sedero estuvieron imbricados con elementos culturales sobresalien-

\footnotetext{
${ }^{22}$ Ibidem, tomo I, p. 91.
} 
tes. La inserción de numerosos velluters ligures en Valencia trajo consigo la implantación efectiva del proceso productivo y de la moda del terciopelo de color negro preferentemente. Ese resultó ser el contenido más evidente de la trasferencia técnica y una de las imágenes diáfanas de esta circulación de saberes la reproduce el salvoconducto concedido a Bartolomeo di Chave el 18 de enero de 1492: "Nos Don Diego de Torres etc. en nom e lor del dit Senyor Rey per autoritat del ofici del qual usam guia e aseguram la persona e béns, robes, coses e mercaderies de vós en Berthomeu de Chave, genovés velluter que stau e habitau de present en la present ciutat de Valencia, ab vestra casa, muller e famflia, e senyaladament totes aquelles coses, e robes, e mercaderies, e una caixa de sedes e velluts, e altres coses que havieu portat de Genova e descarregat en Dènia, e altres que no haiau descarregat que tingau en qualsevol fusta, que salvament e segura pugau anar, venir, estar e habitar ab les dites robes, coses, e mercaderies, e caixa de sedes en la present ciutat de Valencia e en tot lo present regne, en axi que per algú o alguns officials de la present ciutat e regne no puigau ésser pres, marchat ni penyorat, ni detengut la vestra persona ni dits béns ni mercaderies, ni caixa de sedes, per degun crim que vós hajan fet ni per deguns diners que vós desau, ni per degunes marques ni reprassalles atorgades contra béns de genovesos"23.

Pero además la presencia genovesa cristalizó en la fundación rápida entre 1477 y 1479 de un gremio moderno plagado de miembros extranjeros: L'Art de Velluters de Valencia. El nacimiento y el auge posterior de la institución tuvo una dinámica acelerada en comparación con las restantes corporaciones de oficios artesanales en la ciudad. Incluso acabó por convertirse en el vehículo de inserción social y solidaridad civil más efectivo para muchos aprendices y trabajadores asalariados venidos directamente de la Liguria o de los otros territorios foráneos hasta Valencia, atraídos por la expansión del sector. En ese ámbito, la documentación misma ha confirmado de manera explícita que los ligures fueron destacados propulsores en la creación del gremio. El 18 de octubre de 1477, en la casa de Lazzaro Negro, sita en el carrer de les Barques de Valencia, se reunieron 56 maestros velluters en presencia del notario Bernat Sant Feliu para suscribir las

\footnotetext{
${ }^{23}$ ARV, Batllia, 1.160, f. 338 v. Sobre la integración social de los extranjeros en la Península Ibérica véase J. LALINDE ABADfA, L'inserimento dello straniero nelle comunità politiche della Spagna: un profilo giuridico, "Dentro la città. Stranieri e realtà urbane nell'Europa dei secoli XII-XVI", Nápoles, 1989, pp. 47-60.
} 
primeras ordenanzas fundacionales del Arte que -dos años después (en 1479) y con algunas modificaciones- fueron confirmadas por la ciudad y por el rey. Entre el colectivo all congregado estaban además del anfitrión de la asamblea, los genoveses Bartolomeo di Barbagelata, Alberto Borrello, Raffaele di Caneva, Bartolomeo di Facio, Giacomo Gallo, Nicola Giaffi, Matteo Grasso, Giovanni Battista di Rapallo, Raffaele di Rapallo, Lazzaro Risardo, Andrea di Sanguineto y Francesco di Vercelli24.

Desde 1479 a 1524 accedieron a la junta de gobierno del Arte formada por un clavario, dos examinadores y dos veedores renovables todos los años- un colectivo de ligures similar en número al de esos maestros fundadores, destacando la figura de Gerolamo di Roncho, quien ya ocupo el cargo máximo de clavario en $1481^{25}$. Las mismas ordenanzas preescribian desde la creación que los extranjeros asumieran la mitad de los cargos de gobierno en la elección anual. Y algunos completaron su promoción social con la integración incluso en el Consell municipal de Valencia, en calidad de representantes de su oficio (Alberto Borrello en 1488 o Simone di Sori en 1507), o como prohombres de las parroquias (Lazzaro Risardo en 1483 o Andrea di Sanguineto en 1501$)^{26}$. El 4 de septiembre de 1516 , un pleito interno del gremio que debatła su division en dos brazos, corrobora con toda claridad la relevancia social de este fenomeno: "No ignoren vostres senyories com encara que lo ofici de velluters sia stat creat de poch temps, ço és, de quaranta anys poch més o menys, empero és stat crexcut e los mestres de aquell son huy tants en nombre que lo dit ofici és huy lo maior e de més mestres que ningú dels altres oficis. E no resmenys han de saber que jatsia éssent stat portat lo dit art en la present ciutat de Valencia per strangers, ço és, ytalians e genovesos, los quals ab antico han fet e exercit lo dit ofici en la creació del dit ofici" ${ }^{n 2}$.

En verdad, el despegue industrial de la seda en Valencia se habra caracterizado por la eclosión de dos subsectores, una doble combinación técnico-productiva semejante a ese fenomeno de la opera bianca dei veli y de la opera tinta dei drappi que ha descrito Carlo Poni para la Bolonia

\footnotetext{
${ }^{24}$ APPV, notario Bemat Sant Feliu, signalura 1.020.

${ }^{25}$ ACAMSV, Lb. 2.1.3., f. 1 r. (elección je mayurales del 8 de octubre de 1481).

${ }^{26}$ Archivo Municipal de Valencia, Manual; de Consell, A-43 (1483-V-22: f. 128 v.), A-45 (1488-VI-2: f. 143 r.), A-50 (1501-Vi-5: f. :43 r.) y'A-53 (1507-V-31: f. 369 r.).

${ }^{27}$ Pámafo inicial del documento $n^{\circ} 2$ en al apéndice publicado por R. GARClA CARCEL, Las Germanias de Valencia, Barcelona, 1981, pp. 22n-221.
} 
moderna $^{28}$. En ese contexto, el Arte ayudo a promocionar la "obra tintada de paños" desde sus propias ordenanzas corporativas o desde las sentencias favorables en los pleitos contra las otras profesiones de la sederfa local por incompatibilidades en el proceso de producción. La moda textil promovida por los extranjeros reproducía la coyuntura de la propia ciudad de Génova y la homogeneización de los prototipos culturales en Valencia no se hizo de esperar. Alla fine del Quattrocento -dice Carola Ghiara- "più del $60 \%$ dei damaschi e dei velluti commisionati dai mercanti di sete (seaterii) ai tessitori sono di 'colore nigro', e più o meno la stessa percentuale si riscontra tra le pezze di seta vendute in città. Insomma in quello scorcio di secolo, tra la fine del Quattrocento e l'inizio del Cinquecento, il nero stava diventando di moda, rappresentando virtù, austerità, moralità, ma anche rango socia$1 e^{229}$.

Los datos disponibles para Valencia son todavía más espectaculares. En el Manifest de les Sedes de 1475, sólo la producción autóctona de satén negro (sett negre) con 2.378/3/3 varas cortadas de telar o la del terciopelo de igual color (vellut negre) con 1.608/3/1 varas demuestran que tan sólo dos combinaciones representan casi el $75 \%$ del total de tejidos. Con todo, las cifras de 1512 son todavía más sorprendentes. De las $42.292 / 0 / 3$ varas de tejidos que compran los declarantes, $23.788 / 1 / 3$ son de terciopelo negro, es decir, un $56 \%$ del mercado global lo acapara una variedad única. A distancia le siguen alejadas las 4.497/0/1 varas de satén negro, 3.864/3 de damasco negro (domàs negre), las $2.675 / 2 / 2$ de tafetán negro (tafetd negre), y las 1.126 de aterciopelado negro (vellutat negre). Lo que quiere decir que un $85 \%$ de las varas totales compradas y fiscalizadas en la ciudad de Valencia en 1512 eran de color negro. La consonancia internacional del fenómeno y los efectos culturales a larga distancia producidos por los genoveses son realmente interesantes ${ }^{30}$.

Confirmando la tesis original de Huizinga, el mismo Braudel habla explicado que en el siglo XVI se impuso para las clases dominantes de

\footnotetext{
${ }^{28} \mathrm{C}$. PONI, Per la storia del distretto industriale serico di Bologna (secoli XVI-XVX), "Quademi Storici", 73 (1990), pp. 93-167.

${ }^{29} \mathrm{C}$. GHIARA, La tintura nera genovese: La migliore di quante se ne facesse nel mondo, "Seta a Genova 1491-1991", Génova, 1991, p. 22; ID., L'arte tintoria a Genova dal XV al XVII secolo. Tecniche e organizzazione, Génova, 1976.

${ }^{30} \mathrm{G}$. NAVARRO ESPINACH, Industria y artesanado en Valencia, cit., tomo II, figuras 73 74, pp. 549-555. Son las tipologías de tejidos y colores cuantificados en 1475 y 1512 que tienen como base informativa el tomo IV de la misma tesis.
} 
Europa el uso de trajes de paño negro inspirados en los españoles, como una más de las manifestaciones de la preponderancia política y cultural del "Imperio Mundial" del Rey Católico. Dentro de su excelente monografía dedicada a la indumentaria civil catalana de los siglos XIII-XV, Isidra Maranges ha resaltado que el negro fue fundamentalmente el color del duelo desde obras como la novela Blanquerna de Llull (original de 1294): "aquells diners qui eren despeses en les vestidures negres, eren robats als pobres a l'anima del defunt". Todo el mundo llevaba luto incluso por parientes lejanos durante bastante tiempo y también para las ceremonías más tristes de la liturgia cristiana como la Pasión, sobre todo en los tiempos de la Inquisición y de la exaltación de la ortodoxia católica que fueron los años de tránsito del siglo XV al XVI. Indudablemente, es obvio que este sometimiento a un color dominante nunca debió llevarse a cabo sin reticencias y al margen quedaba siempre la inmensa inercia de los pobres, de las resistencias locales, de los compartimentos-estanco regionales. Pero en la fuerza de la Iglesia y del negocio de las élites económicas, más que en arbitrariedades espontáneas, estribó su potencial difusión y triunfo comercial por la Europa mediterránea ${ }^{31}$.

Ahora bien, la promoción del saber técnico artesanal corrió al son de la demanda mercantil. La codificación de los ingredientes fundamentales de la tintura negra en uso ininterrumpido hasta el siglo XVIII ya estaba elaborada en la normativa del Arte dei Tintori di Seta de Génova (1496), y el velluto nero según Paola Massa fue el tipo de tejido más importante de la producción sérica ligur durante todo el siglo $\mathrm{XVI}^{32}$. Los estudios realizados por Flavio Crippa con la reproducción iconográfica de varias representaciones procedentes del Trattato dell'Arte della Seta de Florencia (1487), destacan igualmente el apartado dedicado al teñido en negro de los tejidos de seda ${ }^{33}$. El 14 de enero de 1513 habfa sucedido lo mismo en Valencia según refleja la declaración testimonial del artesano judeoconverso Bernat

\footnotetext{
${ }^{31}$ Cfr. J. Hulzincia, El otoño de la Edad Media, Bucnos Aires, 1947 (orig. 1919), p. 390; F. BRAUDlil., Civilización incalerial, economia y coupitalismo, siglos XV-XVIII, 3 vols., Madrid, 1984, tomo I, p. 270; I. MAkANcilis, La indumentäria civil calalana. Segles XIII-XV, Barcelona, 1991, pp. 110-117.

${ }^{32}$ P. MASSA, La 'fabbrica' dei velluti genovesi da Genove a Zoagli, Génova, 1981, p. 69.

${ }^{33} \mathrm{~F}$. CRIPPA, Del cuocer la seta e del tigner nero, "La Scta", 43/2-3 (1991), pp. 62-63

Para el caso valenciano véase G. NAVARRO ESPINACH, Reconsiruction des lechniques artisanales des teinturiers de soie de Valence XVe-XVle siècles), "Pastcl, Indigo et Autres Plantes Tinctoriales. Passé, Présent et Avenir", Toulouse, en prensa.
} 
Clariana con motivo de un pleito entre velluters y tintoreros de seda recriminando precisamente que: "no y ha nenguns velluters en la present ciutat de Valencia que sàpien tenyir nengunes sedes de color sinó solament negres, les quals tintes negres los dits velluters han aprés de alguns criats de tintorers de seda que aquells se han posat en les cases de aquells" ${ }^{134}$. Con la gran expansión de la demanda comercial se puso en marcha la máxima difusión del saber técnico, y en esos empeños los referentes culturales directos para Valencia no eran otros que los de Génova.

Pero la reorientación en la moda que sufre la economía local valenciana parece tener incluso otro componente técnico de clara influencia ligur. La habilitación de unos 200 tornos de seda en la ciudad en 1479, que serán de 250 a 300 en 1519 (siempre según datos oficiales), mostró de pura necesidad que para los nuevos tejidos pequeños y suntuosos que se fabricaban era gran daño torcer la seda en rama manualmente por la poca resistencia del hilo que se obtenfa, y resultaba mejor utilizar tornos circulares porque producian un hilo más bello, más perfecto y en gran cantidad, destinado a esas nuevas tramas pesadas y complicadas de los terciopelos ${ }^{35}$. De hecho, hasta la torcedura en tornos a la gorra -idonea para la confección de la obra blanca de velos- pasaría a cuestionarse frente a una torcedura con devanadera que algunos calificaban de más adecuada para esas nuevas tramas.

Precisamente, entre 1518 y 1529 se va a desarrollar un pleito de los velluters contra los torcedores de seda que querfan constituirse en oficio separado y defendran poder seguir torciendo la seda a la gorra y no con devanaderas. Entre los argumentos técnicos de los velluters se expresaria que la producción de las tramas gruesas de terciopelos requería un hilo consistente y uniforme tanto para absorber mejor la tinta como para hacer resistente el mismo tejido ya que cuando se torcia a la gorra:"com la hun fil sia gros e lo altre prim,e de aqur.s segueix que com se tiny no pot pendre per igual la tinta, e per la dita rahó com la dita seda és posada en obra de setins e de velluts,la roba que s.és feta...hix tota rugada..e lo pel del vellut..es chafa e no.s pot levar,e de aquella tal roba dura molt poch"36.

\footnotetext{
${ }^{34}$ ACAMSV, Lg. 3.3.1., Procesos, no 4, f. 236 r.

${ }^{35}$ Véasc en profundidad el artículo de F. CRIPPA, Il torcisoio circolare da sela: Evoluzione, machine superstiti, restauri, "Quademi Storici", 73 (1990), pp. 169-212.

${ }^{36}$ ACAMSV, Lg. 3.3.1., Procesos, no 6, f. 1 r.
} 
La detensa de la torcedura cle seda con tornos de devanaderas estaba únicamente relacionada con la fabricación de un hilo que absorbiera mejor la tinta negra y sirviera para dar consistencia a las tramas de los terciopelos. Pero más allá de ese argumento, se confirma un prototipo de maquinaria bastante concreto. En Valencia no se implantará el molino hidráulico de seda a la boloñesa o a la piamontesa, sino que tal y como ocurría en Génova predominaron los molinos de energía humana o animal. Nivel profundo de mimetismo técnico entre Génova y Valencia cuyo origen era tambien resultado de aquella trasferencia cultural y del predominio de una mentalidad empresarial de clara iniciativa genovesa. Implantación del torno o molino de energía humana que jamás debe interpretarse como "retraso tecnológico" o "inercia" frente al uso de la energfa hidráulica en otros lugares. Más bien cabe hablar en parámetros distintos de adaptabilidad empresarial hacia el mercado, donde pequeños cambios en la estructura del torno (mayor número de husos por ejemplo), se unían a un estricto control de la calidad del hilo, y a una mayor rígidez en las relaciones laborales mediante una explotación abusiva de los contratos de aprendizaje. Fórmula presente en Valencia en función de esa lógica empresarial descrita también por Carola Ghiara para Génova: "La continuità tecnologica del mulino a mano genovese non ha impedito che fosse attuata una sia pur parziale rinconversione produttiva nel senso dell'adozione di nuovi tipi di tessuto e della valorizzazione dell'esportazione di semilavorati... (...). Il filatoio genovese e l'organizzazione sociale the ad esso fa riferimento sopravvivono a lungo per i loro pregi di versatilità ed adattabilità ad un mercato in evoluzione" 37 .

El auge del molino a la genovesa en Valencia y la difusión de la tinta negra para colorear los terciopelos a la moda se completó finalmente con la adopción de telares con peines de longitud especial. Cuando se asume la marca genovesa (peines de 20 ligaduras y media) en las ordenanzas de la seda de Valencia, Granada, Sevilla, Córdoba, Málaga o Toledo durante las décadas iniciales del siglo XVI se está implantando evidentemente un prototipo técnico común para las industrias sederas más importantes de la Península Ibérica desde la misma Génova. Con tal trascendencia en Valencia, por ejemplo, que en los capítulos del 21 de mayo de 1511 se

${ }^{37} \mathrm{C}$. GHIARA, Filatoi e filatori a Genova tra XV e XVIII secolo. "Quademi Storici", 5? (1983), p. 137. 
llegará a escribir que la adaptación a esa longitud de peines no podrá llevarse a la práctica al menos hasta Navidad "considerat que en la present ciutat no y ha pintes de aquella amplària com ajen a venir de Jènova" ${ }^{38}$.

\section{TIPOS DE PERFILES SOCIALES ENTRE LOS EMIGRANTES}

Los agentes de esta compleja trasmisión cultural provienen geográficamente o bien de los diversos enclaves en el camino hacia el mar desde Lombardía por Borlasca y Roncho hasta la propia ciudad de Génova, o bien de los mismos centros costeros de la Riviera di Levante. La imagen de esta doble procedencia interior y marítima con eje central en la ciudad de Génova se ha descubierto a través del estudio antroponímico de los apellidos de los emigrantes, utilizando como base del mismo las descripciones de la Liguria de 1453 y 1537, en relación a los toponimi ricorrenti nei cognomina de los tejedores de seda genoveses ya reseñados por Carola Ghiara, así como respecto al mapa de la distribución geográfica de los telares de terciopelos en la República de Génova de 1582, elaborado por Paola Mas$\mathrm{sa}^{39}$. La emigración desde este territorio cruzando el Mediterráneo hacia Valencia parece tener al menos dos motivaciones diferentes -racionalidad empresarial y supervivencia laboral- que permiten identificar a su vez tres perfiles sociales entre los ligures de Valencia: mercaderes capitalistas, maestros artesanos y asalariados.

La primera motivación de la "racionalidad empresarial" de las élites mercantiles encajaŕa en la línea de aquel fenómeno descrito por Luca Mola para explicar la emigración de los sederos luqueses hacia Bolonia y Venecia entre los siglos XIII-XV. Este autor argumenta que el problema "espinoso" de una persistente hemorragía de artesanos de Lucca comportó a la larga una difusión técnica y un incremento de las manufacturas en los centros receptores. Pero, mientras tanto, la emigración paralela de los mercaderes luqueses y los tenaces vínculos que mantuvieron con los artesanos de su 298.

${ }^{38} \mathrm{Cfr}$. G. NAvakro EsíiNa(H, Industria y artesanado en Valencia, cil., tomo I, pp. 297.

${ }^{39}$ El texto de las descripciones de 1453 y 1537 en M. QUAINI, La conoscenza del territorio ligure fra Medio Evo ed Elà Moderna, Gènova, 1981, pp. 63-69 y 71-112. Cfr. adcmás C. GHIARA, Famiglie e carriere artigiane: il caso dei filatori di sela, Génova, 1991, tahla no 7; y P. MASSA, La 'fabbrica' dei velluti genovesi, cit. 
mismo origen devino sobre la base de una frecuencia laboral y de una identidad ciudadana común al menos en el caso veneciano. Tal realidad permitio absorber una gran parte de la pérdida de capital humano por las ciudades de destino gracias a los mecanismos autonomos de inserción social de las propias empresas emigrantes con estrategias de amplio respiro. Es asi que la red comercial de los empresarios luqueses de la seda cubría los mayores centros europeos y ordenaba desde Lucca una extensa estructura internacional de producción con extrema flexibilidad para disfrutar al máximo de las ventajas y alternativas de los diversos mercados ${ }^{40}$. Si a estos planteamientos se añaden los estudios realizados por Giovanna Petti Balbi sobre la emigración de sederos luqueses con los mismos efectos hacia Génova o el ańlisis de Rinaldo Comba en torno a la integración de los sederos genoveses en el área del Piemonte, la imagen del fenomeno aducido se confirma totalmente y encaja de manera perfecta con el tema de los genoveses en Valencia ${ }^{41}$.

Es en ese sentido cómo se entiende la instalación de los empresarios Gavoto, Grasso, Lacomarcino, Machalufo, Palmaro, Roncho, Sanguineto y otros antes de 1475 en la ciudad de Valencia, poniendo en accion sociedades mercantiles cuya intervención en la esfera de la producción local puede seguirse desde múltiples documentos notariales y fiscales ${ }^{42}$. Ellos entregaban materias primas para confeccionar tejidos a muchos pequeños productores, y poselan trabajadores asalariados a su servicio en los telares de su propiedad, en especial obreros de su mismo origen geográfico. Sus empresas claramente motivadas por la nueva centralidad de Valencia en el Mediterráneo genovés fueron punto de destino para crear una red productiva amplia que desde la "escuela de los genoveses" de Valencia se proyectó a otros centros de la Península Ibérica. Por tanto, fue el capital comercial genovés el que revolucionó el ambiente local de la sedeŕa valenciana, donde siguieron dominando paralelamente los pequeños talleres familiares

\footnotetext{
${ }^{40} \mathrm{~L}$. MOLA, L'industria della sela a Lucca nel tardo Medioevo: emigrazione della manodopera e creazione di una rete produttiva a Bologna e Venezia, "La Scla in Europa, secc. XIII-XX" (Settimana Datini), Firenze, 1993, pp. 435-444.

${ }^{4 C f r}$. G. PETT7 BALBI, La presenza lucchese a Genova in elà medioevale, "Lucca e l'Europa degli affari, secoli XV-XVII", Lucca, 1990, pp. 29-43; R. CoMBA, Contadini, signori e mercanti nel Piemonte medievale, Roma, 1988, pp. 143-150.

${ }^{42} \mathrm{G}$. NAVARRO ESPINACH, Industria y artesanado en Valencia, cit., tomo II, capítulo VI, pp. 464.555 .
} 
con modestos costes de produccion, libre disposición del producto acabado y una escasa acumulación de capital.

Pero la iniciativa de los sederos ligures produjo a la larga tras el asentamiento inicial en Valencia un choque de mentalidades que derivó en cierta ruptura interna dentro de la élite empresarial. De hecho, algunos capitalistas como los Gavoto o la compañía de Francesco Palmaro y Andrea di Castello diversificaron los negocios no limitando sus beneficios economicos exclusivamente a la seda, promoviendo formas de libre empresa ajenos totalmente al sistema corporativo que defendfa el grupo de grandes maestros fundadores del Arte en 1477. El choque de mentalidades se produjo pues entre quienes deseaban una tecnologia y unas reglas laborales estables, constituidos en propietarios de pequeños talleres familiares cuya producción se destinaba sobre todo al mercado local de tejidos y al comercio exportador hacia Castilla, y aquellos otros que ajenos al Arte coordinaban libremente procesos de producción mediante la compra de la fibra preparada a unos artesanos, el encargo de las faenas de tintura a otros, el control exhaustivo de la confección en varios talleres de su propiedad, y la distribución final de sus productos al mercado internacional, ignorantes del arte de la seda pero aférrimos persecutores del beneficio capitalista. "Choque de mentalidades" si se quiere entre la élite capitalista versátil y la eternizada aristocracia emprendedora de los oficios.

Ese argumento se comprende, por ejemplo, al observar que no son todos los que declararon sus tejidos en el Manifest de les Sedes de 1475 los que en 1477 intervengan en la fundación del Arte. Algunos genoveses estarán la mayor parte de su vida en el liderazgo político del Arte como es el caso de Alberto Borrello, mientras otros como Franco Gavoto se integrarán siempre en la llamada Cofradia de los Genoveses con su capilla junto al Convento de los Franciscanos de Valencia. Pero entre el caso de Borrello y el caso de Gavoto, personas como Matteo Grasso o Blas Bisso se vinculan simultáneamente al Arte y a la Cofradía, matizando el choque de mentalidades y abriendo los ojos del historiador hacia un perfil social común de "élites económicas" con emergencias políticas alternativas ${ }^{43}$.

\footnotetext{
${ }^{43}$ Compárese el listado de fundadores del Arte en 1477 con los representantes de la Cofradía de los Genoveses que solicitaron el 14 de mayo de 1487 la construcción de una capilla a los franciscanos, en APPV, notario Joan Casanova, signatura 6.164. Cfr. D. IGUAL LUIS, La confraria dels genovesos de València. Una associació interprofessional a les darreries de l'Edat Mitjana, "Moviments socials i dinàmica associativa", Lleida, en prensa.
} 
El 30 de octubre de 1482 comparecieron ante el Batlle General del Regne los comerciantes Francesco Palmaro, Andrea di Castello y Benedetto Pinello para presentar una provisión del rey Fernando contra cierta actuación de los maestros del Arte que junto a las autoridades municipales de Valencia iban por las casas de algunos mercaderes extranjeros como ellos, mirando y reconociendo si las sedas y los brocados que tenían cumplían las ordenanzas corporativas. El rey ante la protesta de los genoveses contra la vigilancia de los maestros corporativos prohibio seguir adelante con esa actitud, puesto que los mercaderes disponían de salvoconductos oficiales ${ }^{44}$. Palmaro, Castello y Pinello fueron promotores de la libre empresa en la sedería frente a los maestros artesanos de igual procedencia ligur que propugnaban la expansión del sistema corporativo, encuadrados en la estructura del Arte. Cuando los negocios de la seda les enriquecieron suficientemente, abandonaron esta intervención sectorial en la esfera de la producción y pasaron a otros intereses como las finanzas ${ }^{45}$. Otro caso altamente ilustrativo lo proporciona el mercader Simone di Sori, velluter genovés avecindado en Valencia en 1498. Su biografía es factible conocerla no sólo desde la documentación notarial (aunque permanezca ajeno a los registros del gremio), sino también a traves de un dietario que escribio su hijo Jeroni Soria -confesando que el apellido ligur de su padre (Sori) le fue corrompido en Valencia y se convirtió en Soria, de igual forma que sucedería en otros casos como el de Borrello convertido en Borrell. Este dietario se inicia el 1508 cuando Jeroni confiesa que su padre Simone le envió a Génova para comprobar si tenía antecedentes hebreos, y continuará hasta 1559 . La familia Sori pertenece a la potente colonia genovesa de Valencia, dedicada a las altas finanzas y que habra llevado a cabo ciertos enlaces matrimoniales con la nobleza local. Es otro caso de mercader capitalista de la seda con estrategias e intereses económicos diversificados y versátiles. El ambiente familiar de origen queda descubierto por el propio hijo en el dietario mencionado: "Venguda de mi Jeroni Soria de Genova a Valençia. A viii de giner, any 1508, vengul de Genova a Valençia perque mon pare Simo de Sori, genovés e natural del loch de Sori, prop de la ciutat de Genova -no obstant que açi en Valençia me corrompen lo nom que per-dir Sori me

\footnotetext{
${ }^{4}$ G. Navarko Espinach, El despegue de la industria sedera, cit., pp. 72-73.

${ }^{45}$ Por poner un ejemplo, véase la prosopografía de Francesco Palınaro con su diversidad de intereses productivos y financieros en la Peninsula Ibérica o en las Islas Canarias tal y como ha reflejado D. IgUAL. LUIS, Valencia y Sevilla, cit., pp. 106-108.
} 
dihuen Soria- lo qual me trameté a Gènova perquè ves si hera yo juheu ho de quina part venia com yo naixqui açr en Valencia, e trobı allà que tots mos oncles heren çiutadins e mercaders de Genova" ${ }^{46}$.

No se ha localizado ningún nombre de mercader o maestro artesano ligur de Valencia entre los elencos de las corporaciones sederas genovesas, una vez inspeccionados los listados de Magistri Artis Filatorum Septe de $1454-1482^{47}$, la nómina de Tintori di Indaco de $1473^{48}$, y la matrícula del Arte Seateriorum Civitatis Janue de $1499^{49}$. En base a esa circunstancia, se puede intuir que la iniciativa empresarial instalada en Valencia debió ser ajena en sus orígenes sociales al cuadro corporativo dirigente en Génova. En el caso de los emigrantes reconocidos como maestros examinados allf se trata de personas cuyas auténticas posibilidades de promoción laboral estaban mejor garantizadas a través del viaje al otro lado del mar que mediante su integración en los ámbitos local, comarcal, regional o incluso interregional, ante la inflacción evidente de los mercados de trabajo urbanos del norte de Italia. Esa puede ser la causa del relativo silencio en las fuentes documentales genovesas sobre la emigración artesanal masiva hacia Valencia. Una clandestinidad evidente por ahora que traslada las reflexiones del historiador a la motivación quizás más importante de este fenómeno de implicaciones internacionales.

El establecimiento de una cadena productiva en Valencia, controlada por la iniciativa empresarial genovesa, estuvo favorecida siempre por la dinámica de subsistencia y recambio de la población de aprendices y trabajadores asalariados que revistió carácter estructural en la ciudad de Génova: "continue immigrazioni per tutto il Cinquecento ed oltre finiranno col porre seri problemi di ordine pubblico e, in epoche di crisi, col fare percepire come discriminazioni a danno dal giovanni genovesi la tradiziona-

\footnotetext{
${ }^{46}$ Dietari de Jeroni Sorria (con prólogo de F. de P. Momblanch Gonzálbez), Valencia, 1960, pp. $45-88$ (cita en p. 41 ).

${ }^{47}$ Archivio di Stato di Genova, Notai Antichi, not. Lazzaro Raggi no 853 (filza 242, 1454. IX-4), not. Lorenzo Costa $n^{\circ} 994$ (filza 334, 1477-X-8), not. Nicola Garumbero no 1.077 (filza 18, 1479-1-15), not. Emanuelle Granello n' 872 (filza 53, 1482-11-4).

"Archivio Storico del Comune di Genova (=ASCG), Magistralo dei Padri del Comune, Atti 1469-76, filza 3, documento 2 "Conti diversi", 1473-VII-12.

"ASCG, Fondo Giulio Pallavicino, ms. 210, Miscellanea di.memoric e famiglie genovesi, ff. 155 r. -177 v.: "...restauratus fuit liber matricula seateriorum annotati quod in ipso stantes seaterios qui in dicto arti fuerunt et infra et pro tempore erant [Anno Domini M CCCC LXXXXVIIII]".
} 
le preferenza del maestri forestieri a reclutare i garzioni dai loro paesi di origine". Esta alta movilidad social en el mercado de trabajo de la ciudad de Génova y entre los núcleos menores de la Liguria tal y como explica Giacomo Casarino, revertía de manera clara en una "massiccia immigrazioni giovanile in città, che fornirà la manodopera necessaria alle industrie della lana e, specialmente, della seta"so.

Por ejemplo, los años de penuria y crisis alimentaria en Génova que van de 1473 a 1488, coinciden con el grueso del flujo migratorio hacia Valencia de un importante colectivo de aprendices, de trabajadores asalariados e incluso de maestros examinados sin posibilidad de negocio propio en la ciudad de donde parten. Así lo confirman la cincuentena de hipótesis de trabajo localizadas sobre todo entre assuntori y famuli del censo prosopográfico aRTigen del Centro di Studi per la Storia della Tecnica, en base al sondeo informático de nombres y cronologías de terciopeleros ligures de

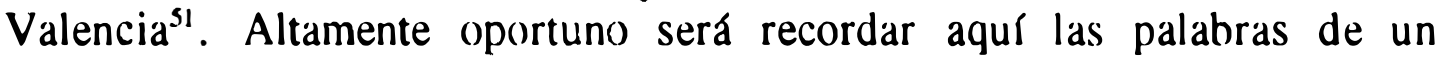
anónimo orador, citado por Casarino, cuando denunciaha en la asamblea del Gran Consejo de Génova a finales de la década de los años 80 del siglo $X V$ que "i figlioli, che son nati di padri ricchi consumando finalmente la roba con fare larghe spese e con lo sfoggiare di continuo nel vivere, e nel vestire, lasciano i figlioli poveri, i quali non sofferendo la povertà vanno in varie parti del mondo e si mettono a fare l'industria, e finalmente arrichiti ritornano nella patria, onde s'erano partiti per esserle con le loro faculta d'ornamento, e di commodos?. Debieron ser los pequeños sujetos economicos, artesanos y asalariados -entre ellos sobre todo fugitivos insolventes como los tejedores de seda denominados rupti confracti ac miserabilesquienes en mayoría viajarían al exilio en Valencia o en otros lugares en busca de mejores condiciones de vida, insertándose en la maquinaría de

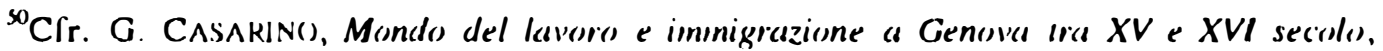
"Strutture familiari, epideınic e inigrwionni", Núpoles, 1984, pp. 451-472; (I)., Nole sul inondo artigiano genovese tra i secoli XV e XVI, "La Storia dei Genovesi", Ginova, 1986, vol. VI, pp. 253-279; y L. GA'TII y G. CASARIN(), Imparare l'arle. Apprendisti nell indusitica serica genovese tra XV e XVI secolo, "Scla a Genova 1491-1991", Gínova, 1991, pp. 18-21. Las dos citas textuales son del priner articulo de esta nota, pp. 453 y 472 respectivainente.

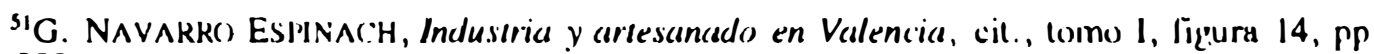
214-222.

${ }^{52}$ G. CASAKJN(), Genova 1473-1488: Jallimenti artigiani Ira crisi alimentari e congiuntura, "Miscellanca Storica Ligure (Studi in Onc,re di Luigi Bulferelli)", Ginova, 1986, pp. 673-70.5.
} 
racionalidad empresarial en funcionamiento y quizás para no volver jamás a su madre patria ${ }^{53}$.

\section{CONCLUSIONES}

Una vez más -emulando a Fernand Braudel tras la lectura del libro manuscrito de Felipe Rúz Martín- devolvamos sus dimensiones y su importancia al "Siglo de los Genoveses" (1557-1627) $)^{\text {s4 }}$. Una dominacion tan discreta y tan sofisticada que escapo durante largo tiempo a la observación de los historiadores y todavía hoy les sigue sorprendiendo. En efecto, la cronología anticipada en Valencia y el peso de las actividades económicas de su colonia genovesa, la convierten en una de las más importantes de la Península Ibérica junto a Sevilla. Entre 1452 y 1500 , se ha podido identificar prosopográficamente a 247 mercaderes genoveses en la ciudad que completan los varios centenares de maestros artesanos y trabajadores de la seda $^{5 s}$. Ciertamente, detrás del éxito de la veintena o treintena de grandes hombres de negocios que protagonizaron aquel "Siglo de los Genoveses", ya no es menester imaginar una fuerte presencia de millares de personas de menor talla preparando el terreno. Por lo menos, el observatorio valenciano ya ha descubierto con su documentación la abundancia real de pequeños mercaderes, artesanos, marinos, corredores y la trascendencia de sus negocios. Verdadera vanguardia de promotores clandestinos de un sistema económico genovés implantado desde el siglo $\mathrm{XV}$ y que perdurará sin duda alguna hasta el declive de la retaguardia conquistadora del espacio peninsular por quienes vinieron después, los grandes capitalistas del XVI.

\footnotetext{
${ }^{53} \mathrm{Cfr}$. J. HEERS, L'exil politique, facteur de transferts économiques (ltalie centrale. XIlleXVe siècle), "Lucca e l'Europa degli affari, secoli XV-XVII", Lucca, 1990, pp. 9-20.

${ }^{M} \mathrm{~F}$. BRAUDEL, Civilización material, cit., tomo III, pp. 124-138.

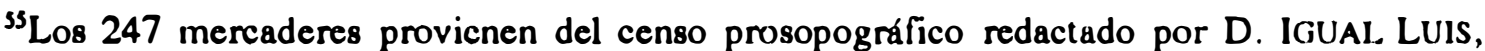
Valencia e ltalia en el siglo XV. Rutas, inercados y hombres de negocios en el espacio económico del Mediterráneo occidental, tesis doctoral en preparación dirigida por el profesor Paulino Iradiel. El listado contrastado final de las biografías reseñadas por Igual y las de nuestra tesis doctoral se publicará en D. IGUAL. LUIS y G. NAVARRO ESPINACH, Estudi antroponímic de l'emigració italiana a Valéncia (segles XV-XVI), "IV Col.loqui d'Onomàstica Valenciana", Ontinyent, 28-30 de setembre de 1995, en prensa.
} 


\section{RÉSUMÉ}

On étudie ici la présence de nombreux soyeux génois à Valence à la fin du XVe siècle: marchands, artisans, travailleurs. Cette présence signifiait un transfert technologique crucial pour la traditionnelle industrie de la soie valencienne d'origine musulmane, qui reconvertit de cette façon son offre génerale de textiles et entraîna son essor commercial. Mais à l'arriere plan, l'immigration internationale et l'importance des affaires génois dans le domaine de la soie, sont en plus un autre exemple de mobilite sociale du bas Moyen Age et contribuent à faire comprendre la formation du système européen moderne de relations dans la Méditerranée.

\section{SUMMARY}

We study here the presence of the numerous Genoese silk dealers in Valencia at the end of the XVth century: merchants, artisans, workers. This settlement signified a crucial economic change in the Valencian traditional silk industry with its Moorish background, and this, in consequence, facilitated reconversion of the textile industry and an increase in its trade. Moreover, international migration and the role of the Genoese silk industry facilitated social mobility during the low Middle Ages and contributed to the origin of the modern European system of relationships in the Mediterranean. 